MS. KÄRT SIMRE (Orcid ID : 0000-0003-0636-2056)

Article type : Regular Article

\title{
Early life exposure to common virus infections did not differ between coeliac disease patients and controls
}

Kärt Simre ${ }^{1,2}$, Oivi Uibo ${ }^{2,3}$, Aleksandr Peet ${ }^{2,3}$, Leena Puustinen ${ }^{4}$, Sami Oikarainen ${ }^{4,5}$, Kirsi Tamminen $^{6}$, Vesna Blazevic ${ }^{6}$, Vallo Tillmann ${ }^{2,3}$, Anu-Maaria Hämäläinen ${ }^{7}$, Taina Härkönen ${ }^{8,9}$, Heli Siljander ${ }^{8,9}$, Suvi M. Virtanen ${ }^{10-12}$, Jorma llonen ${ }^{13}$, Heikki Hyöty ${ }^{4,5}$, Mikael Knip ${ }^{8,9,12,14}$, Raivo Uibo ${ }^{1}$ on behalf of the DIABIMMUNE Study Group*

${ }^{1}$ Department of Immunology, Institute of Biomedicine and Translational Medicine, University of Tartu, Tartu, Estonia, ${ }^{2}$ Children's Clinic of Tartu University Hospital, Tartu, Estonia, ${ }^{3}$ Department of Pediatrics, University of Tartu, Tartu, Estonia, ${ }^{4}$ Faculty of Medicine and Life Science, University of Tampere, Tampere, Finland, ${ }^{5}$ Fimlab Laboratories, Pirkanmaa Hospital District, Tampere, Finland, ${ }^{6}$ Vaccine Research Center, Faculty of Medicine and Life Sciences, University of Tampere, Tampere, Finland, ${ }^{7}$ Jorvi Hospital, Helsinki University Hospital, Espoo, Finland, ${ }^{8}$ Children's Hospital, University of Helsinki and Helsinki University Hospital, Helsinki, Finland, ${ }^{9}$ Research Programs Unit, Diabetes and Obesity, University of Helsinki, Helsinki, Finland, ${ }^{10}$ Department of Public Health Solutions, National Institute for Health and Welfare, Helsinki, Finland, ${ }^{11}$ Faculty of Social Sciences/Health Sciences, University of Tampere, Tampere, Finland, ${ }^{12}$ Center for Child Health Research, Tampere University and University Hospital, and The Science Center of Pirkanmaa Hospital District, Tampere, Finland, ${ }^{13}$ Immunogenetics Laboratory, Institute of Biomedicine, University of

This article has been accepted for publication and undergone full peer review but has not been through the copyediting, typesetting, pagination and proofreading process, which may lead to differences between this version and the Version of Record. Please cite this article as doi: 10.1111/apa.14791

This article is protected by copyright. All rights reserved. 
Turku and Clinical Microbiology, Turku University Hospital, Turku, Finland, and ${ }^{14}$ Folkhälsan Research Center, Helsinki, Finland

${ }^{*}$ Members of the Group are listed in Appendix S1

Short title: Early life infections and coeliac disease

Author for correspondence: Raivo Uibo, MD, PhD, Department of Immunology, Institute of Biomedicine and Translational Medicine, University of Tartu, 19 Ravila Street, Tartu 50411, Estonia, E-mail: raivo.uibo@ut.ee.

\section{ABSTRACT}

\section{Aim}

Our aim was to compare the presence of various common viruses (rhinovirus, enterovirus, adenovirus, Epstein-Barr virus, cytomegalovirus, norovirus, parechovirus) in stool and nasal swab samples as well as virus-specific antibodies in serum samples between children who developed coeliac disease and controls.

\section{Methods}

A case-control study was established based on the DIABIMMUNE Study cohorts. During the study eight Estonian children and 21 Finnish children aged 1.5-5 years developed coeliac disease and each was matched with a disease-free control. Nasal swabs and stool samples were taken at the age of 3-6 months and the serum samples at the time of diagnosis.

\section{Results}

Rhinovirus ribonucleic acid was detected in the nasal swabs from five coeliac disease children, but none of the control children $(p=0.05)$. There were no statistically significant differences in the level of viral antibodies between cases and controls. Enterovirus

This article is protected by copyright. All rights reserved. 
immunoglobulin G class antibodies were found more frequently in the Estonian than in the Finnish children $(63 \%$ versus $23 \%, p=0.02)$.

\section{Conclusion}

This study did not find any marked overall differences in laboratory confirmed common viral infections between the children who developed coeliac disease and the controls. However, rhinovirus infections were detected slightly more often in those patients who developed coeliac disease.

\section{KEY WORDS}

Childhood infections; coeliac disease; enterovirus; rhinovirus; viral infections

\section{KEY NOTES}

- There were no significant differences in laboratory confirmed common viral infections between the children who developed coeliac disease and the controls at the age of $1.5-5$ years.

- Rhinovirus ribonucleic acid was detected in nasal swab samples of five coeliac disease children, but in none of the disease-free controls $(p=0.05)$.

- Enterovirus immunoglobulin G class antibodies were found more frequently in the Estonian than Finnish children (63\% versus 23\%).

\section{INTRODUCTION}

Coeliac disease is a systemic gluten-driven immune-mediated disorder in genetically predisposed subjects carrying the human leukocyte antigen (HLA) DQ2 and, or DQ8 (1). The

This article is protected by copyright. All rights reserved. 
pathogenesis of coeliac disease is complex and not completely understood, but several environmental and immunological factors are likely to be involved (2).

Viral infections are one possible environmental factor. There is growing evidence that coxsackieviruses (3) and herpes viruses (4) can be involved in the processes leading to the development of different autoimmune diseases, including coeliac disease. Kemppainen et al showed a relationship between gastrointestinal infections and increased risk of coeliac disease in genetically susceptible children (5). Some data has suggested that herpes viruses may have a protective effect on the development of coeliac disease (6). It is also possible that the pathogenesis of childhood coeliac disease is influenced by the cumulative effect of early-life infections and not just by one specific microbial or viral agent $(7,8)$. Most of these studies have been epidemiological (8) and based on parental reports $(5,7)$ and there have been very few experimental (9) and laboratory (6) investigations that have shown this relationship. However, experimental work by Bouziat et al suggests that the reovirus may be related to the development of coeliac disease (9).

In our previous study, we reported that by the age of 12 months children who later developed coeliac disease had more episodes of infections with fever than control children (10). The limitation of this study was that the illnesses were reported by the children's parents without laboratory confirmed microbial or viral diagnosis. The aim of our current study was to detect viruses in stool and nasal swab samples before the diagnosis and virusspecific antibodies in serum samples at the diagnosis of coeliac disease. We also wanted to compare the frequency of infections in the disease group and disease-free controls with similar genetic background and thereby to assess their involvement in the development of coeliac disease.

This article is protected by copyright. All rights reserved. 


\section{MATERIALS AND METHODS}

\section{Study subjects}

Our analysis formed part of the international prospective observational DIABIMMUNE Study. The study aimed to test the hygiene hypothesis and explore its role in the development of type 1 diabetes and other autoimmune diseases. It was originally carried out in Estonia, Finland and Russian Karelia from September 2008 to October 2013. As there were no biopsy confirmed coeliac disease cases in Russia, that country was not included in this study.

The study included two cohorts: a birth cohort, which observed children from birth up to the age of 3 years and a young children cohort who were examined for the first time at the age of 3 years and observed to the age of 5 years. The two cohorts comprised different children who were observed in parallel during the study period. The exact recruitment criteria have previously been described (10).

As shown in Figure 1, altogether 2,714 infants from maternity hospitals in Estonia and 3,105 infants in Finland were recruited to the birth cohort. All these children were analysed for type 1 diabetes and coeliac disease associated HLA DR/DQ alleles (11) from cord blood. If the child had eligible HLA genotypes, he or she was invited to follow-up programme. In total, 258 HLA eligible children in Estonia (61\% of all eligible) and 305 in Finland (43\% of all eligible) completed the 3-year follow-up programme. In the young children cohort, 1,681 children from Estonia and 1,575 children from Finland were studied at the age of 3 years and 1,363 $(81 \%)$ and 1,384 (88\%) children, respectively, attended the follow-up visit at the age of 5 years. They were all genotyped for type 1 diabetes and coeliac disease associated HLA, but recruitment was not based on their genotype.

During the DIABIMMUNE Study, blood samples were collected by venipuncture at each visit, and serum were separated by centrifugation and stored in aliquots at $-70^{\circ} \mathrm{C}$ for further use.

This article is protected by copyright. All rights reserved. 
Venous blood samples were collected at 3, 6, 12, 18, 24 and 36 months of age in the birth cohort and at 3 and 5 years of age in the young children cohort.

In the birth cohort the parents were asked to collect monthly stool samples at home, starting from the age of 1 month. The samples were stored in home freezers at $-20^{\circ} \mathrm{C}$ immediately after the collection until they were transported frozen to the laboratory for long-term storage at $-80^{\circ} \mathrm{C}$. Also in the birth cohort nasal swabs were collected at study visits by research personnel, starting from the age of 3 months, and stored immediately at $-20^{\circ} \mathrm{C}$ and later at $80^{\circ} \mathrm{C}$ for long-term storage.

In both cohorts all children were screened for coeliac disease by analysing immunoglobulin A (IgA) tissue transglutaminase antibodies (tTG). If there was an equivocal result, for example due to low serum volume, haemolytic sample or the IgA-tTG assay could not detect any $\lg A$, other tests, including immunoglobulin $G$ ( $\lg G)$ tTG assays, were applied. The exact protocol has previously been described (10). If the result of the antibody test indicated a suspicion of coeliac disease, the diagnosis was confirmed in line with the European Society for Paediatric Gastroenterology, Hepatology and Nutrition guidelines (1) by abnormal morphology of a small intestinal biopsy, in accordance with the Marsh classification modified by Oberhuber et al (12).

During the study period, 29 children developed coeliac disease including two Estonian and seven Finnish children in the birth cohort and six Estonian and 14 Finnish children in the young children cohort. There were no statistical differences in the mean age at the initial seroconversion to IgA-tTG positivity between Estonian and Finnish children in the birth cohort (3.0 versus 2.3 years, $p=0.12$ ) or in the young children's cohort (3.6 versus 3.4 years, $\mathrm{p}=0.18)(10)$.

For every child with coeliac disease, one disease-free control child from the same DIABIMMUNE cohort was selected and matched pair-wise for the coeliac disease specific

This article is protected by copyright. All rights reserved. 
HLA DR/DQ genotype, country of birth, time of birth and sex. The complete characterisation of the coeliac disease and control groups has been published previously (10).

Enterovirus, norovirus, parechovirus and rhinovirus ribonucleic acid (RNA) were analysed in the birth cohort from the stool samples collected at the age of 3, 4, 5 and 6 months. In addition, enterovirus, parechovirus and rhinovirus RNA were analysed from the nasal swab samples collected at the age of 3 and 6 months in the same cohort. IgA and IgG antibodies against the norovirus, adenovirus, enterovirus and $\lg G$ antibodies against Epstein-Barr virus and cytomegalovirus were measured from the serum sample of the children with coeliac disease at the time point of seroconversion to positivity for autoantibodies associated with coeliac disease in both cohorts. The corresponding serum samples from the control children were collected at the same age.

\section{Laboratory methods}

The HLA DR/DQ genotypes were analysed with a polymerase chain reaction (PCR)-based lanthanide labelled oligonucleotide hybridisation method in the Immunogenetics Laboratory, University of Turku, Finland, using time-resolved fluorometry for detection as described previously (13).

For screening coeliac disease the autoantibodies associated with coeliac disease were analysed. IgA-tTG was measured using ImmunoCAP EliA fully automated solid-phase fluoroenzyme immunoassay technology (Phadia AB, Uppsala, Sweden) in accordance with a specific and previously described protocol (10). We considered samples with values higher than $10 \mathrm{EliA} \mathrm{U} / \mathrm{ml}$ positive. The analyses were performed in the Department of Immunology, University of Tartu, Estonia.

We screened for enterovirus and rhinovirus RNA from stool and nasal swab samples using real time reverse transcription PCR (RT-PCR). In addition, we tested for parechovirus and

This article is protected by copyright. All rights reserved. 
norovirus RNA in the stool samples using specific RT-PCR methods (parechovirus also from nasal swab). Stool samples were suspended in a concentration of $10 \%$ in HANKS solution (Sigma-Aldrich, Missouri, USA) and RNA was extracted using the viral RNA kit (Qiagen, Hilden, Germany). QuantiTect Probe reagents (Qiagen, Hilden, Germany) were used according to the manufacturer's instructions for amplification of virus RNA. All the samples were run in triplicate and, if any of the reaction was positive, that sample was regarded as positive for the tested virus. Primer and probe sequences, as well as the concentrations in the reactions, were reported by Krogvold et al (14). That study recorded two primer pairs for enterovirus detection, but in our study the primer pair of fwd 636 and rev 4- was used. The analysis was carried out in the Virus Laboratory, University of Tampere, Finland.

The analysis of norovirus, adenovirus and enterovirus $\lg A$ and $\lg G$ antibodies in serum was carried out in the Virus Laboratory, University of Tampere, Finland, by indirect enzymelinked immunosorbent assay (ELISA). All samples were tested in pairs. Samples from the case and control child were included in the same test run, without knowing the case-control status of the child. The level of anti-viral IgA and IgG is expressed as enzyme immunoassay units (EIU).

Briefly, 96-well half-area polystyrene plates (Corning Incorporated, New York, USA) were used for norovirus antibody analyses and Nunc-Immuno MaxiSorp plates (Thermo Fisher Scientific, Massachusetts, USA) for adenovirus and enterovirus antibody analyses. For norovirus antibody analyses, the plates were coated with norovirus virus-like particle antigens at a concentration of $1 \mu \mathrm{g} / \mathrm{ml}$ in phosphate-buffered saline $(\mathrm{pH} 7.2)$ as previously described (15). For adenovirus antibody analyses an adenovirus hexon antigen was used at a concentration of $0.32 \mu \mathrm{g} / \mathrm{ml}$ in phosphate-buffered saline $(\mathrm{pH} 7.2)(16)$ and for enterovirus a sucrose gradient purified coxsackievirus B4 was used at a concentration of $0.76 \mu \mathrm{g} / \mathrm{ml}$ in carbonate buffer (17). Norovirus antibodies were analysed using 1/200 (IgA) and 1/4000 (lgG) serum dilutions in 1\% milk + 0.05\% Tween 20 (MP Biomedicals, Illkirch, France) in phosphate-buffered saline and adenovirus and enterovirus antibodies using 1/100 (IgA) and

This article is protected by copyright. All rights reserved. 
1/2000 (IgG) dilutions in phosphate-buffered saline supplemented with $1 \%$ bovine serum albumin (Sigma-Aldrich, Missouri, USA), 2\% sodium chloride and $0.05 \%$ Tween 20 . For norovirus $\lg \mathrm{A}$, the detection antibodies were goat anti-human IgA-horseradish peroxidase (Pierce cat PA1-74395, Thermo Fisher Scientific, Massachusetts, USA) and for IgG goat anti-human IgG-HRP (Invitrogen cat 627120, Invitrogen, California, USA). For adenovirus and enterovirus IgA, Dako P0216 rabbit anti-human IgA-HRP (Dako, Glostrup, Denmark) and for IgG Dako P0214 rabbit anti-human IgG-HRP (Dako, Glostrup, Denmark) were used. Absorbance at $490 \mathrm{~nm}$ (norovirus, adenovirus) or $492 \mathrm{~nm}$ (enterovirus) was measured on a Victor2 microplate reader (PerkinElmer, Massachusetts, USA).

Cut-off limits for the virus antibody analyses were determined by arrangement of the optical density results in ascending order to generate a histogram (Figure S1). The abrupt increase of the optical density values was used to separate positive and negative values. The arbitrary negative values were used to calculate the final cut-off using the formula: the mean of the arbitrary optical density negative value + three standard deviations (SD). The cut-off is shown with an arrow on the histograms. All the values above the set cut-off value were considered as positive.

For cytomegalovirus IgG and Epstein-Barr virus viral capside antigen IgG detection we used ELISA in accordance with the manufacturer's protocol, by employing the LUCIO-Sero ELISA Cytomegalovirus IgG and the LUCIO-Sero ELISA Epstein-Barr VCA IgG (nal von minden $\mathrm{GmbH}$, Moers, Germany). The results were calculated according to the manufacturer's instructions. Equivocal cytomegalovirus IgG results were demonstrated in a child with coeliac disease in the birth cohort from Estonia and this child was excluded from the final analysis.

This article is protected by copyright. All rights reserved. 


\section{Statistical analysis}

The statistical analysis was performed with R software for Windows 2016 (R Foundation for Statistical Computing, Vienna, Austria). To analyse differences in antibody levels between the coeliac disease and control groups we used the paired t-test or the Wilcoxon signed-rank test. The paired t-test was used for norovirus and enterovirus IgA antibodies comparisons in the birth cohort and enterovirus IgG antibodies comparisons in both cohorts in cases where IgA-tTG was higher than $100 \mathrm{U} / \mathrm{ml}$. The Wilcoxon signed-rank test was used for all other comparisons between the coeliac disease and control groups. Odds ratios (OR) were used to assess the risk of coeliac disease. Conditional logistic regression was applied to calculate adjusted ORs (aOR). 95\% confidence intervals $(\mathrm{Cl})$ were used to estimate the precision of the aORs. Correlations between the level of virus IgA or IgG antibodies and the level of IgAtTG were analysed with the non-parametric Spearman test. We compared the antibody levels between the Estonian and Finnish children with the Mann-Whitney-Wilcoxon test. To compare the number of cases with antibodies or viruses in the different study groups, the Fisher's exact test or the chi-square test was applied. The Shapiro-Wilk normality test was used to determine if the data had a normal distribution. A p value of less than 0.05 was considered significant.

\section{Ethical considerations}

The study was conducted in accordance with the ethical guidelines of the Declaration of Helsinki. The local ethical committees in Estonia and Finland approved the study. All the parents gave written, informed consent for their child to participate in the study.

This article is protected by copyright. All rights reserved. 


\section{RESULTS}

\section{Viruses in stool and nasal swab samples}

In the birth cohort, $13 / 120(11 \%)$ of the serial stool samples from children who developed coeliac disease were virus positive, compared to $14 / 120(12 \%)$ of the stool samples from the controls $(p=1.0)$. From the cases $5 / 43(12 \%)$ nasal swabs were virus positive, compared to none of the 36 nasal swab samples from the controls $(p=0.06)$. At least one viral agent was detected in either the stool or nasal swab samples of $7 / 9(78 \%)$ children in the coeliac disease group and in 6/9 (67\%) children in the control group $(p=1.0)$. The rhinovirus was the virus that was detected most frequently in both the stool and nasal swab samples. At the age of 3 and 6 months, $8 / 33$ (24\%) samples from the children with coeliac disease and 7/32 (22\%) samples from the control children contained some rhinovirus when the stool and nasal swab samples were combined. There were 5/18 (28\%) rhinovirus positive nasal swabs in the cases and none in the 16 controls $(p=0.05)$. In the stool samples, the corresponding figures were $3 / 15(20 \%)$ and $7 / 16(44 \%)(p=0.25)$. Enterovirus and parechovirus were not detected in any sample (Figure 2).

\section{Viral antibody differences between the coeliac disease and control group}

There were no statistically significant differences in the level of viral antibodies, or the number of positive cases, between the case and control children in the birth cohort or the cohort of young children or when the two cohorts were combined (Figure 3). When the norovirus, adenovirus and enterovirus IgA positive cases were combined in the birth cohort, the case children had a mean of 1.6 infections and the controls had a mean of 1.2 infections $(p=0.55)$. The mean number of positive tests for $\lg G$ antibodies to these viruses was 1.4 and $1.0(p=0.33)$, respectively. In the cohort of young children the mean number of positive tests did not differ between the coeliac disease and control groups ( 1.7 versus 1.8 for $\lg A, p=0.67$, and 1.5 versus 1.7 for $\lg G, p=0.38$ ). There was no difference in the cytomegalovirus and

This article is protected by copyright. All rights reserved. 
Epstein-Barr virus IgG antibodies between the groups. When using the aOR and $95 \% \mathrm{Cl}$ none of the measured virus antibodies affected the risk of coeliac disease in the birth cohort, in the young children cohort or in the combined cohort (data not shown). There was no association between the level of virus $\lg A$ or $\lg G$ antibodies and the level of IgA-tTG (data not shown).

When we only took coeliac disease cases into account, where IgA-tTG was higher than 100 $\mathrm{U} / \mathrm{ml}$, there were no differences in viral antibodies between the coeliac disease and control group.

\section{Viral antibody differences between Estonia and Finland}

The study included 42 children from Finland and 16 children from Estonia. When the different virus antibodies were compared between the two countries, enterovirus IgG class antibodies were found to be much more frequent in Estonian children (63\% versus $23 \%$, $p=0.02$ ). The same difference was seen in average enterovirus IgG antibody levels (34.5 EIU versus 19.0 EIU, $p=0.01$ ) (Figure 4). A similar, but non-significant, trend was also seen in enterovirus $\lg \mathrm{A}$ antibodies ( $56 \%$ versus $38 \%, p=0.54$ and 61.2 EIU versus $35.3 \mathrm{EIU}$, $\mathrm{p}=0.31)$. Other virus antibodies did not differ between the countries.

\section{DISCUSSION}

This study was an extension of our earlier study where we compared the occurrence of prospectively reported infections between children who developed coeliac disease and matched control children with no disease. In that study the children who developed coeliac disease during the first 3 years of life had more infections with fever during their first 12 months (10). In our current study we set out to analyse which of the most common infections might be involved, by detecting enterovirus, parechovirus, norovirus and rhinovirus in stool

This article is protected by copyright. All rights reserved. 
and nasal swab samples collected from case and control children before the diagnosis of coeliac disease. We also measured IgA and IgG antibodies in the serum to norovirus, adenovirus, enterovirus and IgG antibodies to cytomegalovirus and Epstein-Barr virus in the same groups at the time of the diagnosis of coeliac disease in the cases.

The main finding was that the overall level and frequency of the gastrointestinal virus antibodies did not differ between the patients and controls. Some previous studies have been published that have reported possible relationships between different gastrointestinal infections and coeliac disease. Kemppainen et al found that gastrointestinal infections might increase the risk of coeliac disease in genetically susceptible children (5). Stene et al (18) reported in their prospective study that rotavirus infections might be involved. We did not add the rotavirus to the analyses in this study since the rotavirus vaccination coverage was very different between the cases and controls and there were very few pairs that had the same vaccination status. There have been no studies about a potential association between the norovirus and coeliac disease. Some studies have shown an association between adenovirus type 12 (Ad 12) and coeliac disease (19), but this was not confirmed in other studies (20). However, all these studies are quite old. Carlsson et al studied the cord blood of the mothers whose offspring later developed coeliac disease and did not find any association between enterovirus infection during pregnancy and the development of coeliac disease during childhood (21). On the other hand, one study reported enterovirus genomes in intestinal biopsies collected from coeliac disease patients (22). The Generation R Study found that herpesviruses may have a protective effect in the development of coeliac disease (6). We could not find such an association in our study by measuring IgG antibodies against cytomegalovirus and Epstein-Barr virus.

However, when we combined seropositivity for at least one of the tested viruses in serum, these tended to be more common in coeliac disease patients than in controls, with a mean of 1.6 versus 1.2 infections per child, in the birth cohort. This may indicate that there was some

This article is protected by copyright. All rights reserved. 
cumulative effect of early infections, as indicated in previous epidemiological studies $(7,8,10)$.

In nasal swab samples, rhinoviruses were detected slightly more frequently in coeliac disease patients than in controls, but this was not the case for stool samples. Rhinoviruses replicate in the respiratory tract at relatively low temperatures, but they are not known to be able to replicate in the intestinal mucosa where the temperature is substantially higher. Therefore, respiratory samples are considered to be the most reliable sample type for rhinovirus detection. We cannot exclude the possibility that certain rhinovirus species, such as species $\mathrm{C}$, could also replicate at higher temperatures, such as those present in the intestinal mucosa (23). Notably, the main rhinovirus receptor intercellular adhesion molecules-1 (24) is also expressed in intestinal mucosa in coeliac disease (25). One could hypothesise that rhinovirus infection may increase the expression of intercellular adhesion molecules-1 in the intestinal mucosa and thereby facilitate leukocyte migration towards infection sites, including gliadin sensitised T cells.

When we compared the Finnish and Estonian children, this revealed that the Estonian were more likely to test positive for enterovirus IgG. Importantly, the mean levels of the antibodies were significantly higher in the Estonia cohort than in Finland. This finding was in line with our previous studies (26). It has been reported that type 1 diabetes is more frequent in Finland (27) than in Estonia (28). Enteroviruses may play a role in the pathogenesis of autoimmune beta-cell destruction in type1 diabetes (29). We have previously shown that the 5-year cumulative incidence of childhood coeliac disease was significantly higher in Finland than in Estonia $(0.77 \%$ versus $0.27 \%, p=0.01)(10)$. Accordingly, both coeliac disease and type 1 diabetes are more frequent in Finland than Estonia, but enterovirus antibodies are less frequent. The low prevalence of enterovirus infections in Finland may cause deficient immune protection by transferred maternal antibodies in early childhood, which might make Finnish children more susceptible to early enterovirus-induced diseases, as proposed in earlier studies (26).

This article is protected by copyright. All rights reserved. 
When we considered the relationship between the low prevalence of enterovirus infection and the high prevalence of type 1 diabetes and coeliac disease, we felt that this may reflect the hygiene hypothesis. This was because in countries where enterovirus infections are frequent, children had strong immune responses to these viruses, and the incidence of type 1 diabetes and coeliac disease was lower (30). This fits with the so-called polio hypothesis reported in a previous study (31). That study reported that in cases of poliomyelitis, a wellknown disease caused by an enterovirus, severe paralytic complications were more common in countries where the circulation of the virus in the background population was less frequent.

Our study had some limitations, which need to be considered when interpreting the results. First, the number of coeliac disease cases was relatively low and this limited the statistical power. Although the original DIABIMMUNE Study was prospective, the current survey is a retrospectively matched case-control study that has some disadvantages related to that type of studies. In addition, we did not have the chance to collect serial stool and nasal swab samples from every child we studied at all time points. The limited number of study samples reflects the problems related to collecting samples from young children. In addition, the present study did not cover all the possible viruses that could be linked to coeliac disease.

The main strength of our study was the prospective design in the DIABIMMUNE Study and the well-synchronised and carefully followed study protocols in both countries. Another strength was the careful matching of the children with coeliac disease and the control subject. Importantly all the coeliac disease cases were confirmed by small intestinal biopsy and specific laboratory analyses were carried out in one laboratory.

\section{CONCLUSION}

This study did not find any marked difference in laboratory confirmed common viral infections, namely enterovirus, adenovirus, Epstein-Barr virus, cytomegalovirus, norovirus

This article is protected by copyright. All rights reserved. 
and parechovirus infections, between the children who developed coeliac disease and their matched controls. However, rhinovirus infections were observed to be slightly more frequent in the coeliac disease patients than in the controls. As our study population was small, larger studies are needed to confirm this particular finding. In addition, our study confirms earlier findings of a significantly higher prevalence of enterovirus infections in Estonian children than in their Finnish peers.

\section{ABBREVIATIONS}

aOR, adjusted ORs; Cl, confidence interval; EIU, enzyme immunoassay unit; ELISA, enzyme-linked immunosorbent assay; HLA, human leukocyte antigen; IgA, immunoglobulin A; IgG, immunoglobulin G; OR, odds ratios; RNA, ribonucleic acid; RT-PCR, real time reverse transcription polymerase chain reaction; SD, standard deviations; tTG, tissue transglutaminase antibodies

\section{FUNDING}

The project was funded by the European Commission (7th Framework Programme, project 202063), the Estonian Research Council grant IUT20-43 and PUT1382 and the Academy of Finland (the Centre of Excellence in Molecular Systems Immunology and Physiology Research, 2012-2017, Decision Nos. 250114 and 284597).

\section{CONFLICTS OF INTEREST}

The authors report no conflicts of interest.

This article is protected by copyright. All rights reserved. 
References:

1. Husby S, Koletzko S, Korponay-Szabó IR, Mearin ML, Phillips A, Shamir R, et al. European Society for Pediatric Gastroenterology, Hepatology, and Nutrition guidelines for the diagnosis of coeliac disease. J Pediatr Gastroenterol Nutr 2012; 54: $136-60$.

2. Kagnoff M.F. Celiac disease (A gastrointestinal disease with environmental, genetic, and immunologic components). Gastroenterol Clin North Am 1992; 21: 405-25.

3. Massilamany C, Koenig A, Reddy J, Huber S, Buskiewicz I. Autoimmunity in picornavirus infections. Curr Opin Virol 2016; 16: 8-14.

4. Barzilai O, Sherer Y, Ram M, Izhaky D, Anaya JM, Shoenfeld Y. Epstein-Barr virus and cytomegalovirus in autoimmune diseases: are they truly notorious? A preliminary report. Ann N Y Acad Sci 2007; 1108: 567-77.

5. Kemppainen KM, Lynch KF, Liu E, Lönnrot M, Simell V, Briese T, et al. Factors that increase risk of celiac disease autoimmunity after a gastrointestinal infection in early life. Clin Gastroenterol Hepatol 2017; 15: 694-702.

6. Jansen MA, van den Heuvel D, van der Zwet KV, Jaddoe VW, Hofman A, Escher JC, et al. Herpesvirus infections and transglutaminase type 2 antibody positivity in childhood: the generation R Study. J Pediatr Gastroenterol Nutr 2016; 63: 423-30.

7. Mårild K, Kahrs CR, Tapia G, Stene LC, Størdal K. Infections and risk of celiac disease in childhood: a prospective nationwide cohort study. Am J Gastroenterol 2015; 110: 1475-84.

8. Beyerlein A, Donnachie E, Ziegler AG. Infections in early life and development of celiac disease. Am J Epidemiol 2017; 186: 1277-80.

9. Bouziat R, Hinterleitner R, Brown JJ, Stencel-Baerenwald JE, Ikizler M, Mayassi T, et al. Reovirus infection triggers inflammatory responses to dietary antigens and development of celiac disease. Science 2017; 356: 44-50.

10. Simre K, Uibo O, Peet A, Tillmann V, Kool P, Hämäläinen AM, et al. Exploring the risk factors for differences in the cumulative incidence of coeliac disease in two

This article is protected by copyright. All rights reserved. 
neighboring countries: the prospective DIABIMMUNE study. Dig Liver Dis 2016; 48: 1296-301.

11. Peet A, Kool P, Ilonen J, Knip M, Tillmann V; DIABIMMUNE Study Group. Birth weight in newborn infants with different diabetes-associated HLA genotypes in three neighbouring countries: Finland, Estonia and Russian Karelia. Diabetes Metab Res Rev 2012; 28: 455-61.

12. Oberhuber G, Granditsch G, Vogelsang H. The histopathology of coeliac disease: time for a standardized report scheme for pathologists. Eur J Gastroenterol Hepatol 1999; 11: $1185-94$.

13. Hermann R, Turpeinen H, Laine AP, Veijola R, Knip M, Simell O, et al. HLA DR-DQencoded genetic determinants of childhood-onset type 1 diabetes in Finland: an analysis of 622 nuclear families. Tissue Antigens 2003; 62: 162-9.

14. Krogvold L, Edwin B, Buanes T, Frisk G, Skog O, Anagandula M, et al. Detection of a low-grade enteroviral infection in the islets of langerhans of living patients newly diagnosed with type 1 diabetes. Diabetes 2015; 64: 1682-7.

15. Nurminen K, Blazevic V, Huhti L, Räsänen S, Koho T, Hytönen VP, et al. Prevalence of norovirus Gll-4 antibodies in Finnish children. J Med Virol 2011; 83: 525-31.

16. Lönnrot M, Korpela K, Knip M, Ilonen J, Simell O, Korhonen S, et al. Enterovirus infection as a risk factor for beta-cell autoimmunity in a prospectively observed birth cohort: the Finnish Diabetes Prediction and Prevention Study. Diabetes 2000; 49: 1314-8.

17. Hyöty H, Hiltunen M, Knip M, Laakkonen M, Vähäsalo P, Karjalainen J, et al. A prospective study of the role of coxsackie B and other enterovirus infections in the pathogenesis of IDDM. Childhood Diabetes in Finland (DiMe) Study Group. Diabetes 1995; 44: 652-7.

18. Stene LC, Honeyman MC, Hoffenberg EJ, Haas JE, Sokol RJ, Emery L, et al. Rotavirus infection frequency and risk of celiac disease autoimmunity in early childhood: a longitudinal study. Am J Gastroenterol 2006; 101: 2333-40.

This article is protected by copyright. All rights reserved. 
19. Lähdeaho ML, Parkkonen P, Reunala T, Mäki M, Lehtinen M. Antibodies to E1b proteinderived peptides of enteric adenovirus type 40 are associated with celiac disease and dermatitis herpetiformis. Clin Immunol Immunopathol 1993; 69: 300-5.

20. Lawler M, Humphries P, O'Farrelly C, Hoey H, Sheils O, Jeffers M, et al. Adenovirus 12 E1A gene detection by polymerase chain reaction in both the normal and coeliac duodenum. Gut 1994; 35: 1226-32.

21. Carlsson AK, Lindberg BA, Bredberg AC, Hyöty H, Ivarsson SA. Enterovirus infection during pregnancy is not a risk factor for celiac disease in the offspring. $J$ Pediatr Gastroenterol Nutr 2002; 35: 649-52.

22. Oikarinen M, Tauriainen S, Oikarinen S, Honkanen T, Collin P, Rantala I, et al. Type 1 diabetes is associated with enterovirus infection in gut mucosa. Diabetes 2012; 61: 687-91.

23. Tapparel C, Sobo K, Constant S, Huang S, Van Belle S, Kaiser L. Growth and characterization of different human rhinovirus $\mathrm{C}$ types in three-dimensional human airway epithelia reconstituted in vitro. Virology 2013; 446: 1-8.

24. Staunton DE, Merluzzi VJ, Rothlein R, Barton R, Marlin SD, Springer TA. A cell adhesion molecule, ICAM-1, is the major surface receptor for rhinoviruses. Cell 1989; 56: 84953.

25. Sturgess RP, Macartney JC, Makgoba MW, Hung CH, Haskard DO, Ciclitira PJ. Differential upregulation of intercellular adhesion molecule-1 in coeliac disease. Clin Exp Immunol 1990; 82: 489-92.

26. Viskari H, Ludvigsson J, Uibo R, Salur L, Marciulionyte D, Hermann R, et al. Relationship between the incidence of type 1 diabetes and enterovirus infections in different European populations: results from the EPIVIR project. J Med Virol 2004; 72: 610-7. 27. Harjutsalo V, Sund R, Knip M, Groop PH. Incidence of type 1 diabetes in Finland. JAMA 2013; 310: 427-8.

This article is protected by copyright. All rights reserved. 
28. Teeäär T, Liivak N, Heilman K, Kool P, Sor R, Paal M, et al. Increasing incidence of childhood-onset type 1 diabetes mellitus among Estonian children in 1999-2006.

Time trend analysis 1983-2006. Pediatr Diabetes 2010; 11: 107-10.

29. Yeung WC, Rawlinson WD, Craig ME. Enterovirus infection and type 1 diabetes mellitus: systematic review and meta-analysis of observational molecular studies. BMJ 2011; $342-50$.

30. Bach JF. Infections and autoimmune diseases. J Autoimmun 2005; 25 Suppl: 74-80.

31. Viskari HR, Koskela P, Lönnrot M, Luonuansuu S, Reunanen A, Baer M, et al. Can enterovirus infections explain the increasing incidence of type 1 diabetes? Diabetes Care 2000; 23: 414-6.

Figure 1. Study outline with relevant data about subjects and methods

Figure 2. Virus test results in stool and nasal swab samples in the birth cohort at the age of 3 and 6 months

(• - coeliac disease child, $\diamond$ - control child, En - enterovirus, Pa - parechovirus, Rh rhinovirus, NoV - norovirus, CD - coeliac disease)

Figure 3. Number of positive cases and the median (shown as a dot), minimum (minimum point of the line) and maximum (maximum point of the line) level of IgA and IgG antibodies in the coeliac disease and control groups

(CD - coeliac disease child)

This article is protected by copyright. All rights reserved. 
Figure 4. Number of positive cases and the median (shown as a dot), minimum (minimum point of the line) and maximum (maximum point of the line) level of IgA and IgG antibodies between Estonian and Finnish children

( ${ }^{*}$ - statistically significant difference)

Figure S1 (a-f). Histograms showing optical density results in ascending order and an arrow showing the cut-off of positive and negative values - a) norovirus IgA, b) norovirus $\lg G, c)$ adenovirus $\lg A, d$ ) adenovirus $\lg G, e)$ enterovirus $\lg A, f)$ enterovirus $\lg G$

(OD - optical density) 
Birth cohort

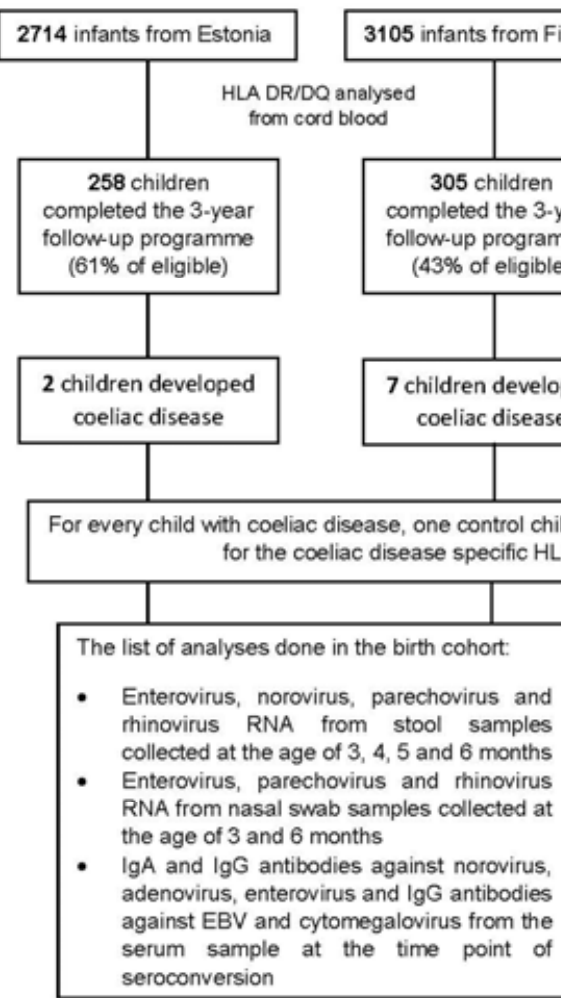

Young children cohort

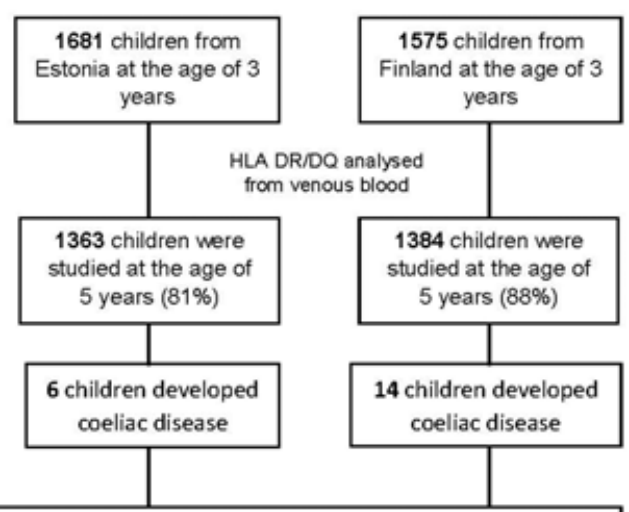




\begin{tabular}{|c|c|c|c|c|c|c|c|c|c|c|c|c|c|c|c|}
\hline \multirow{3}{*}{\multicolumn{2}{|c|}{$\begin{array}{l}\text { Children with } \\
\text { positive results }\end{array}$}} & \multicolumn{3}{|c|}{$\begin{array}{l}\text { Nasal swab samples at } \\
\text { the age of } 3 \text { months }\end{array}$} & \multicolumn{4}{|c|}{$\begin{array}{c}\text { Stool samples } \\
\text { at the age of } 3 \text { months }\end{array}$} & \multicolumn{3}{|c|}{$\begin{array}{l}\text { Nasal swab samples at } \\
\text { the age of } 6 \text { months }\end{array}$} & \multicolumn{4}{|c|}{$\begin{array}{l}\text { Stool samples } \\
\text { at the age of } 6 \text { months }\end{array}$} \\
\hline & & En & $\mathrm{Pa}$ & $\mathrm{Rh}$ & En & $\mathrm{Pa}$ & NoV & $\mathrm{Rh}$ & En & $\mathrm{Pa}$ & $\mathrm{Rh}$ & En & $\mathrm{Pa}$ & NoV & $\mathrm{Rh}$ \\
\hline & & & & $\stackrel{\bullet}{\bullet}$ & & & - 0 & $\begin{array}{l}0 \\
0 \\
-0 \\
-0\end{array}$ & & & • & & & -0 & $\begin{array}{r}0 \\
0 \\
-\quad 0\end{array}$ \\
\hline $\begin{array}{r}\text { Children } \\
\text { negative } r\end{array}$ & $\begin{array}{l}\text { with } \\
\text { esults }\end{array}$ & 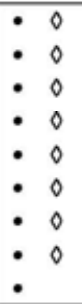 & $\begin{array}{ll}\cdot & 0 \\
\cdot & 0 \\
\cdot & \end{array}$ & 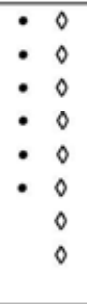 & $\begin{array}{ll} & 0 \\
- & 0 \\
- & 0 \\
- & 0 \\
\cdot & 0 \\
- & 0 \\
- & 0 \\
- & 0\end{array}$ & $\begin{array}{ll}- & 0 \\
- & 0 \\
- & 0 \\
- & 0 \\
- & 0 \\
- & 0 \\
- & 0 \\
- & 0\end{array}$ & $\begin{array}{ll}- & 0 \\
- & 0 \\
- & 0 \\
- & 0 \\
- & 0 \\
- & 0 \\
& 0\end{array}$ & $\begin{array}{ll}\cdot & 0 \\
- & 0 \\
- & 0 \\
- & 0 \\
- & \\
\cdot & \end{array}$ & $\begin{array}{ll}\cdot & 0 \\
\cdot & 0 \\
\cdot & 0 \\
\cdot & 0 \\
\cdot & 0 \\
\cdot & 0 \\
\cdot & 0 \\
\cdot & 0\end{array}$ & $\begin{array}{ll}\cdot & 0 \\
- & 0 \\
- & \end{array}$ & $\begin{array}{ll} & 0 \\
- & 0 \\
- & 0 \\
- & 0 \\
- & 0 \\
- & 0 \\
- & 0 \\
& 0\end{array}$ & 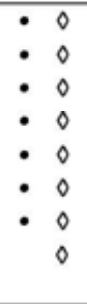 & 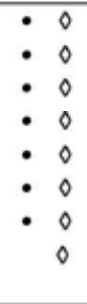 & $\begin{array}{ll}\cdot & 0 \\
- & 0 \\
- & 0 \\
- & 0 \\
- & 0 \\
- & 0 \\
& 0\end{array}$ & $\begin{array}{ll}-1 & 0 \\
- & 0 \\
- & 0 \\
- & 0 \\
- & 0\end{array}$ \\
\hline $\begin{array}{l}\text { Proportion } \\
\text { of positive } \\
\text { cases }\end{array}$ & $\begin{array}{l}\mathrm{CD} \\
\text { Coetrol }\end{array}$ & $\begin{array}{l}0 / 9 \\
0 / 8\end{array}$ & $0 / 3$ & $\begin{array}{l}3 / 9 \\
0 / 8\end{array}$ & $\begin{array}{l}0 / 8 \\
0 / 8\end{array}$ & $\begin{array}{ll}0 / 8 & \\
& 0 / 8 \\
\end{array}$ & $1 / 8$ & $2 / 8$ & $\begin{array}{l}0 / 9 \\
0 / 8\end{array}$ & $0 / 4$ & $2 / 9 / 8$ & $\begin{array}{l}0 / 7 \\
0 / 8\end{array}$ & $0 / 7$ & $\begin{array}{ll}1 / 7 & \\
1 / 8\end{array}$ & $\begin{array}{l}1 / 7 \\
3 / 8\end{array}$ \\
\hline
\end{tabular}

This article is protected by copyright. All rights reserved. 


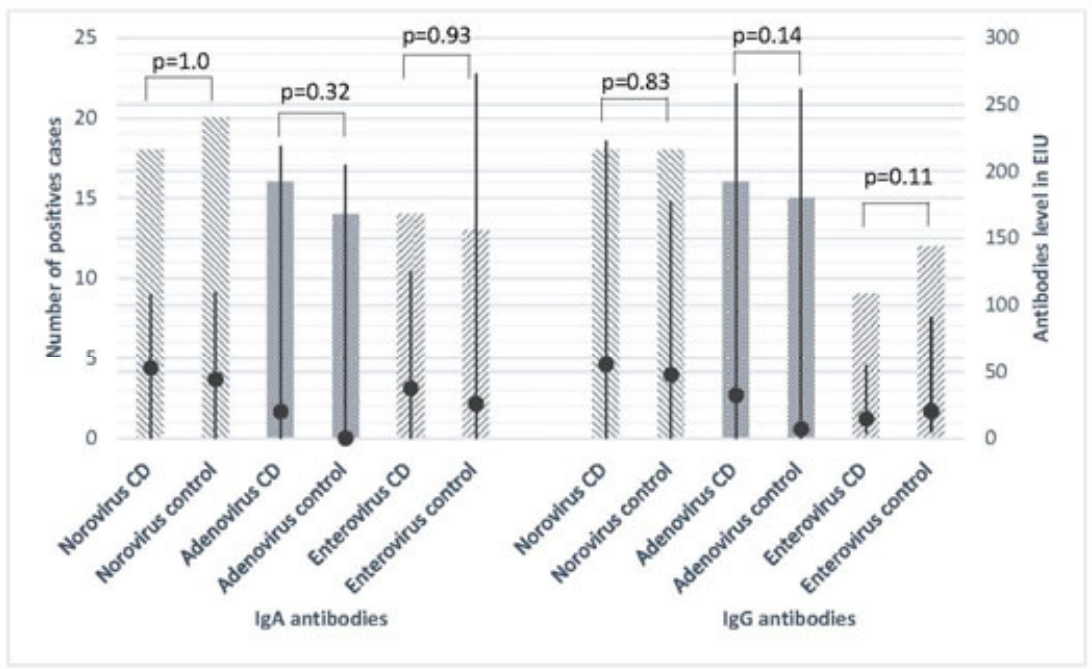

This article is protected by copyright. All rights reserved. 


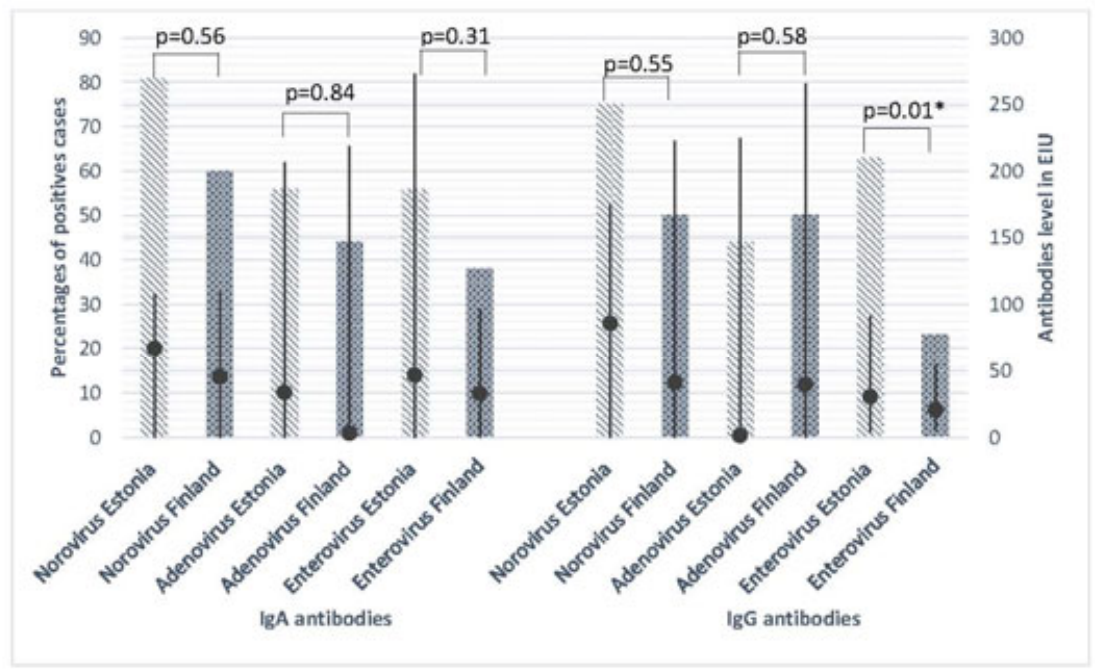

This article is protected by copyright. All rights reserved. 